\title{
Comparing direct and indirect fluidized bed gasification: Effect of redox cycle on olivine activity
}

\author{
G. Aranda Almansa \\ A. van der Drift \\ B.J. Vreugdenhil \\ H.J.M. Visser \\ C.F. Mourao Vilela \\ C.M. van der Meijden
}

September 2013

ECN-W--13-034 


\section{Environmental Progress}

\& Sustainable Energy

\section{[tcbiomass2013] Comparing direct and indirect fluidized bed gasification: Effect of redox cycle on olivine activity}

\begin{tabular}{|r|l|}
\hline Journal: & Environmental Progress \\
\hline Manuscript ID: & Draft \\
\hline Wiley - Manuscript type: & Original Manuscript \\
\hline Date Submitted by the Author: & n/a \\
\hline Complete List of Authors: & $\begin{array}{l}\text { Aranda Almansa, Guadalupe; ECN, Biomass and Energy Efficiency } \\
\text { van der Drift, Bram; ECN, Biomass and Energy Efficiency } \\
\text { Vreugdenhil, Berend; ECN, Biomass and Energy Efficiency } \\
\text { Visser, Rian; ECN, Biomass and Energy Efficiency } \\
\text { Vilela, Carlos; ECN, Biomass and Energy Efficiency } \\
\text { van der Meijden, Christiaan; ECN, Biomass and Energy Efficiency }\end{array}$ \\
\hline Keywords: & Biomass, Gasification, Catalyst, Iron, Mass Transport \\
\hline Alternate Keywords: & \multicolumn{2}{|c|}{} \\
\hline \multicolumn{2}{|c|}{} \\
\hline
\end{tabular}


TCBiomass, Chicago, September 2013

\title{
[tcbiomass2013] Comparing direct and indirect fluidized bed gasification: Effect of redox cycle on olivine activity
}

\author{
G. Aranda ${ }^{1}$ a , A. van der Drift ${ }^{1}$, B.J. Vreugdenhil ${ }^{1}$, H.J.M. Visser ${ }^{1}$, C.F. Vilela ${ }^{1}$, C.M. van der \\ Meijden ${ }^{1}$ \\ ${ }^{1}$ Energy research Centre of The Netherlands (ECN), Unit Biomass \& Energy Efficiency, P.O. Box 1, 1755 ZG \\ Petten, The Netherlands.
}

\begin{abstract}
Fluidized bed gasification processes are generally considered a good choice for biomass and waste because of its fuel flexibility. Furthermore, it is a relatively low-temperature highly efficient process operating at $700-900^{\circ} \mathrm{C}$ compared to e.g. coal-based entrained flow processes that mostly operate at $1400-1600^{\circ} \mathrm{C}$. Indirect fluidized bed gasification is becoming increasingly popular for some applications due to the possibility of producing a $\mathrm{N}_{2}$-free gas without the need for an air separation unit, as well as complete conversion of the fuel. ECN has developed MILENA indirect gasification, in which gasification and combustion are physically separated, but both reactors are placed in the same vessel.

This paper aims to compare the concepts of direct- and indirect (MILENA) fluidized bed gasification on the activity of olivine as bed material. With this purpose, oxidation/reduction cycles have been simulated in a direct gasifier in order to determine the effect of olivine pre-oxidation on its performance in terms of tar destruction and oxygen transport. Results show that olivine pre-oxidation mainly enhances the capacity of oxygen transport of the bed material, which further improves the catalytic effect of iron in olivine towards tar destruction. Oxygen transport capacity of olivine has been quantified as $E R=0.25$ at the maximum initial $\mathrm{CO}_{2}$ peak, and it has been estimated that $20-25 \%$ wt. of iron in olivine is able to transfer oxygen. On the other hand, it has been found that MILENA operating conditions are equivalent to the point of initial maximum peak of $\mathrm{CO}_{2}$ in the devolatilization stage. This means that oxygen transport capacity of olivine is kept at its maximum due to the continuous combustion/gasification cycles, and olivine is kept activated by cyclical migration of iron into the surface and subsequent fast reduction.
\end{abstract}

KEYWORDS: Indirect gasification, MILENA gasifier, olivine, catalytic tar destruction, oxygen transport, redox cycle.

\footnotetext{
${ }^{\text {a }}$ Author for correspondence: G. Aranda, aranda@ecn.nl
} 


\section{INTRODUCTION}

Indirect gasification is defined as the process where heat production takes place outside the reactor where heat is needed. That means that gasification/pyrolysis and combustion take place in different reactors, mass and energy being transferred between them. Indirect gasification allows high fuel conversion, and better control and process optimization. Furthermore, in indirect gasification the combustion products (flue gas) and gasification products (syngas or producer gas) are not mixed, which means that the producer gas is not diluted with $\mathrm{N}_{2}$ coming from the air used for combustion, and thus, is suitable for synthesis applications after proper cleaning and upgrading. MILENA is an indirect gasification technology developed at the Energy Research Centre of The Netherlands $(\mathrm{ECN})$. Work since the late $1990 \mathrm{~s}$ has resulted in a $25 \mathrm{~kW}_{\text {th }}$ lab-scale input capacity and a pilot plant of $800 \mathrm{~kW}_{\text {th }}$ capacity. MILENA technology incorporates several improvements with respect to existing indirect gasification concepts, e.g. one single vessel for both reactors (cheaper, easier to pressurize, and with less heat loss), a single bed material circulation mass flow restriction to avoid imbalances, easy process control, higher efficiency due to a minimum amount of gas/steam for the gasification reactor, and the implementation of a settling chamber instead of cyclone for gas/bed material separation to reduce start-up issues and increase the ability to cope with flow disturbances [1].

There are different available bed materials for both direct and indirect fluidized bed gasification processes. Among them, olivine is an attractive option in terms of catalytic activity, attrition resistance and cost. Olivine is a silicate mineral in which magnesium and some iron cations are embedded in the silicate tetrahedral. Part of the iron in olivine is present as $\mathrm{Fe}$ (III) oxides $\left(\alpha-\mathrm{Fe}_{2} \mathrm{O}_{3}, \mathrm{MgFe}_{2} \mathrm{O}_{4}\right)$ and the other part is present as $\mathrm{Fe}$ (II) inside the olivine structure [2]. Olivine is reported to increase $\mathrm{H}_{2}$ production and decrease $\mathrm{CO}$ and $\mathrm{CH}_{4}$ contents compared to the use of silica sand, due to its catalytic effect on the reforming of hydrocarbons and tar and the promotion of the water-gas shift (WGS) reaction [2][3][4]. Olivine is claimed to have a double effect on tar destruction. On the one hand, it acts as a catalyst for tar and hydrocarbon reforming. On the other hand, it behaves as an oxygen carrier that transfers oxygen from the combustor to the gasifier via a redox cycle [2][3][5][6], making oxygen available for partial oxidation of gaseous species in the gasification zone [3][7]. The improved catalytic activity of olivine is related to the presence of iron at the surface of the material [8]. Both the phase in which $\mathrm{Fe}$ is present and its location in the olivine structure play a strong role in the catalytic activity of the bed material [9]. Since iron in olivine is highly mobile under alternating oxidizing and reducing environments (i.e. indirect gasification conditions), changes in gas atmosphere influence the phase composition of olivine, particularly the surface concentration and oxidation state of iron [2][5]. 
With this background, this paper aims to study the role of oxygen transport on the activity of olivine when used as bed material, which will allow a deeper understanding of the differences between direct- and indirect (MILENA) fluidized bed gasification concepts. With this purpose, oxidation/reduction cycles similar to those taking place during indirect gasification have been simulated in a direct gasifier. Results of pre-oxidized olivine from simulated indirect gasification were compared with those from direct gasification conditions without previous oxidation of olivine. Performance of olivine has been evaluated in terms of producer gas composition and production and composition of tars. Unlike previous works, the overall performance of olivine in terms of producer gas composition and tar production will be assessed under realistic gasification conditions.

\section{EXPERIMENTAL SECTION}

Gasification tests were carried out in a lab-scale direct fluidized bed reactor of $78 \mathrm{~mm}$ inner diameter $(102 \mathrm{~mm}$ freeboard diameter) and $1630 \mathrm{~mm}$ total height (900 $\mathrm{mm}$ corresponding to freeboard). The reactor is electrically heated and insulated in order to compensate for heat losses.

Rettenmaier Räucher Gold HBK 750/2000 beech wood has been used in all gasification tests as feedstock. This biomass, which is also the fuel typically used in MILENA indirect gasifier, has a constant quality and particle size distribution in the range of $750 \mu \mathrm{m}$ to $2 \mathrm{~mm}$ [1]. Moreover, Rettenmaier beech wood is a clean biomass fuel, with $10.2 \%$ wt. moisture (wet basis), and $1 \%$ wt. ash (dry basis). Thermochemical properties of this biomass fuel can be found at the ECN's Phyllis database [10].

Bed material in the fluidized bed tests is Austrian olivine used previously in MILENA gasification. This material, whose composition can be found elsewhere [1], contains a surface layer rich in calcium and iron formed due to interaction with biomass ash which showed improved gasification performance with respect to fresh olivine in terms of producer gas composition and tar production in previous MILENA gasification tests [1].

Table 1 Experimental schedule of gasification tests $\left(T=880^{\circ} \mathrm{C}\right)$.

\begin{tabular}{|c|c|c|c|c|c|c|c|}
\hline \multirow{2}{*}{ Test } & Biomass & Stage & $\begin{array}{c}\dot{m}_{b} \\
(\mathrm{~g} / \mathrm{h})\end{array}$ & $\begin{array}{c}\dot{m}_{\mathrm{N}_{2}} \\
(\mathrm{NL} / \mathrm{min})\end{array}$ & $\begin{array}{c}\dot{m}_{\text {air }} \\
(\mathrm{NL} / \mathrm{min})\end{array}$ & $\begin{array}{c}\dot{m}_{\mathrm{H}_{2} \mathrm{O}} \\
(\mathrm{g} / \mathrm{h})\end{array}$ & $\begin{array}{c}\text { Time } \\
(\mathrm{min})\end{array}$ \\
\hline 1 & Beech wood & Devolatilization & 248 & 14 & 0 & 68 & 420 \\
\hline \multirow{3}{*}{2} & \multirow{3}{*}{ Beech wood } & Oxidation 1 & 0 & 0 & 14 & 0 & 111 \\
\cline { 3 - 9 } & & Devolatilization 1 & 237 & 14 & 0 & 68 & 98 \\
\cline { 3 - 9 } & & Oxidation 2 & 0 & 0 & 14 & 0 & 101 \\
\cline { 3 - 9 } & & Devolatilization 2 & 237 & 14 & 0 & 68 & 104 \\
\hline
\end{tabular}

The experimental schedule described in Table 1 was carried out in the direct fluidized bed gasifier in order to compare direct and indirect gasification concepts. In test 1 , reactor was pre-heated under an inert $\mathrm{N}_{2}$ atmosphere (that means that the bed material was not subjected to any pre-treatment), and a single devolatilization stage 
under similar conditions as MILENA gasification was carried out throughout the test. On the contrary, in test 2 , several cyclic oxidation/reduction cycles were performed in the fluidized bed in order to simulate redox processes taking place during indirect MILENA gasification. The operating conditions of each stage are described below:

- Devolatilization: With the aim of accurately simulating MILENA riser conditions, steam was used as gasifying agent at a steam/biomass mass ratio $(S / B)$ equal to 0.3 . In all cases, approximately $0.25 \mathrm{~kg} / \mathrm{h}$ biomass $\left(\dot{m}_{b}\right)$ was fed into the reactor, fuel feeding screw being calibrated for beech wood prior to tests. Steam flow rate was balanced with $14 \mathrm{~L} / \mathrm{min}$ fluidizing $\mathrm{N}_{2}$ in order to keep atmosphere as similar as possible as MILENA riser, thus avoiding oxidation of tars due to the presence of air. Fluidization velocity was selected as 5 times the minimum fluidization velocity.

- Oxidation stage: $\mathrm{N}_{2}$ flow was switched to air $(14 \mathrm{~L} / \mathrm{min})$, and both biomass feeder and steam generator were turned off. Char built up (in case there was a previous devolatilization stage) was completely oxidized.

The procedure followed for experimental tests was as follows: prior each test, $3 \mathrm{~kg}$ of biomass was weighed and introduced in the fuel bunker, and approximately $1 \mathrm{~kg}$ bed material was weighed and introduced in the reactor. A reactor temperature of $880^{\circ} \mathrm{C}$ was selected in all tests as the average of riser and combustor temperatures in MILENA gasifier $\left(850^{\circ} \mathrm{C}\right.$ and $920^{\circ} \mathrm{C}$, respectively). In all cases, $1 \mathrm{~L} / \mathrm{min} \mathrm{N}_{2}$ is used to flush the fuel feeding screw. During each test, experimental data (volumetric flow rates of gases, bed temperatures and pressures, and producer gas composition) are logged and exported for further processing. Additionally, producer gas composition is also analyzed by micro-GC. Tar samples obtained by Solid Phase Adsorption (SPA) were taken regularly in each test to determine any trends in tar production/composition. Producer gas flow rate is further calculated from a $\mathrm{N}_{2}$ molar balance. Moreover, both bed material and cyclone content were weighed and sampled after each test in order to perform mass balances. Biomass remaining in the hopper was taken out and weighed for an accurate calculation of the mass flow rate.

The activity/behavior of the bed material in this work has been evaluated by the following parameters: producer gas composition, and concentration and distribution of composition of tars according to the ECN classification $[8][11]$.

\section{RESULTS AND DISCUSSION}

\subsection{Effect of olivine pre-oxidation: producer gas composition}

Results of comparison between tests 1 and 2 (the latter simulating gasification/combustion cycles taking place during MILENA indirect gasification) are plotted in Figures 1- 4. It must be remarked that, for the sake of 
comparison, $\mathrm{X}$ axis has been normalized in all figures so that time 0:00 corresponds to the beginning of devolatilization stage in all cases.
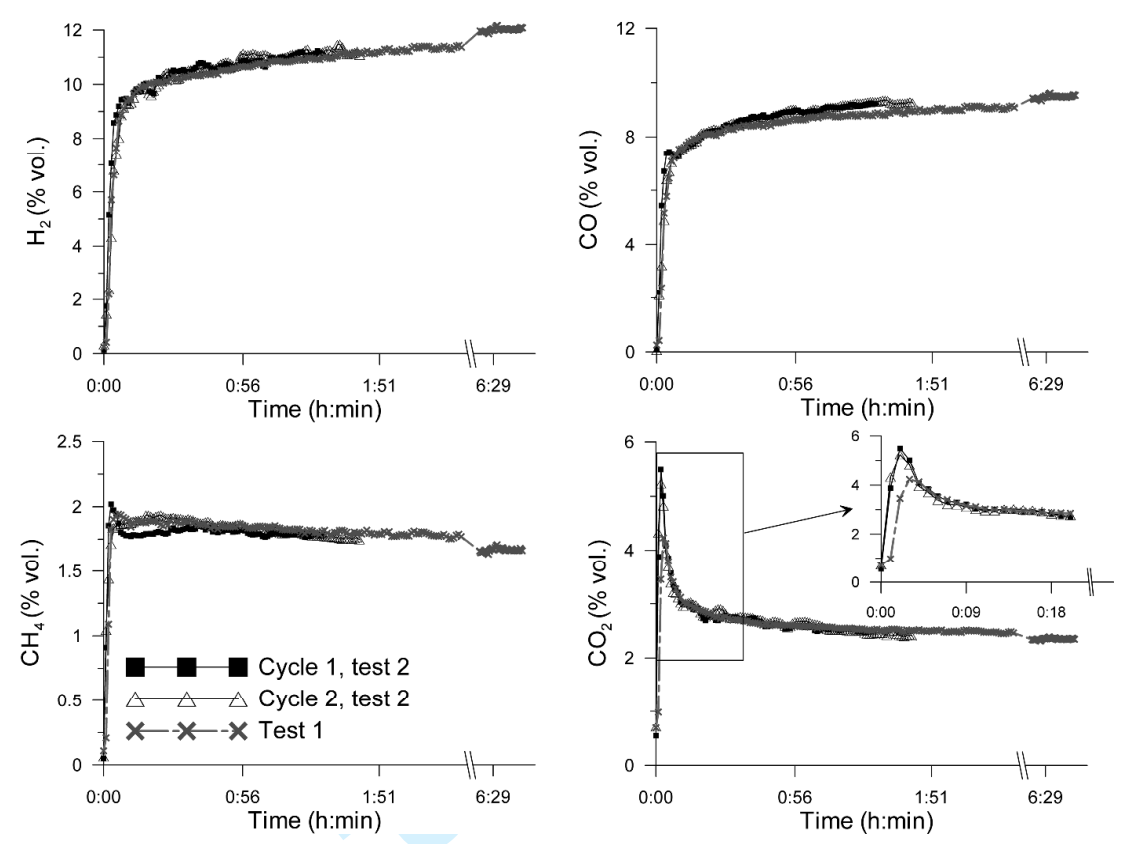

Figure 1 Effect of olivine pre-oxidation on distribution of producer gas composition.

In Figure 1 it can be observed that olivine leads in all cases to a fast increase of $\mathrm{H}_{2}$ and $\mathrm{CO}$ content in the first instants of devolatilization, probably due to the enhancement of the extent of the reforming reactions. However, pre-oxidized olivine produces a more intense peak of $\mathrm{CO}_{2}$ within the first minutes of operation. This initial $\mathrm{CO}_{2}$ peak indicates the fast reduction of the previously oxidized olivine, leading to the release of $\mathrm{CO}_{2}$ and $\mathrm{H}_{2} \mathrm{O}$ into the process, thus revealing the effect of oxygen transport of olivine via redox cycle. In consistency with these results, Lancee et al. observed during TGA tests that the whole oxidation/reduction cycle is divided into two separate processes with different time scales, namely a very fast process in which $80 \%$ wt. is transferred in a few seconds, and another one of slower, converging change of mass with time [5]. The minor $\mathrm{CO}_{2}$ peak found for non-pre-oxidized olivine is probably due to the partial oxidized state of the material after tests in MILENA gasifier. As reduction stage proceeds, two simultaneous phenomena occur. On the one hand, reduced olivine acts as a catalyst for tar destruction. On the other hand, the initial olivine surface composition is progressively recovered, since migrated iron to the olivine surface during the previous oxidation stage goes back to the bulk of the olivine particle [5]. Steady increase in time of $\mathrm{H}_{2}$ and $\mathrm{CO}$ concentrations observed in Figure 1 seems to indicate a minor effect of the latter process.

\subsection{Effect of olivine pre-oxidation: tar production}

Comparison of total tar production as a function of pre-treatment of olivine is shown in Figure 2. Firstly, it must be taken into account that the relatively low values of tar production are due to the high dilution of producer gas 
in fluidizing nitrogen. It can be noticed that total tar production decreases in time regardless of the pretreatment conditions of the bed material due to the progressive reduction of iron oxides. However, pre-oxidized olivine leads to a significant decrease of total tar concentration with respect to non-previously oxidized material even at the first instants of operation. This trend is more noticeable in the case of bed oxidation with char combustion (cycle 2).

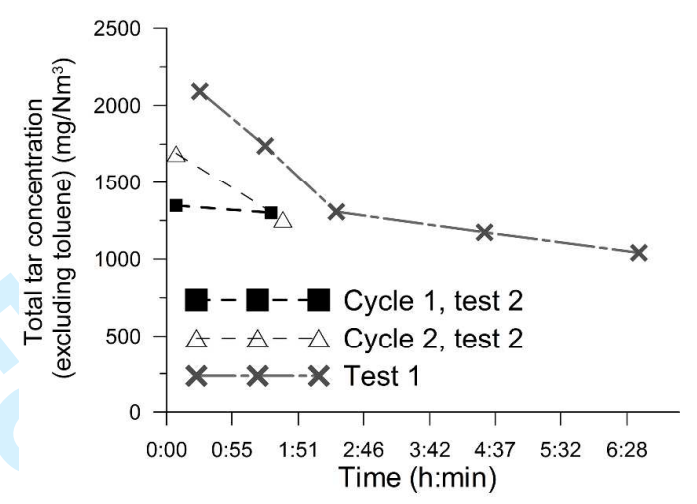

Figure 2 Effect of olivine pre-oxidation on total tar concentration.

Since both pre-oxidized and non-pre-oxidized olivine leads to similar $\mathrm{H}_{2}$ and $\mathrm{CO}$ content in the producer gas, the decrease in tar production might be attributed to the higher oxygen transport performed by pre-oxidized olivine during the first instants of devolatilization. This way, tars, as well as $\mathrm{H}_{2}$ and $\mathrm{CO}$, are partly oxidized via reduction reactions of iron oxides. Results are consistent with findings by Devi [8], who determined that pretreatment of olivine by heating at $900^{\circ} \mathrm{C}$ in presence of air (which leads to segregation of $\mathrm{Fe}$ at the surface of olivine, and change of the oxidation state from $\mathrm{Fe}^{2+}$ to $\mathrm{Fe}^{3+}$ ) increased naphthalene conversion with respect to untreated olivine. Devi also observed that $\mathrm{H}_{2} \mathrm{O}$ and $\mathrm{CO}_{2}$ have an enhancing effect on tar conversion, whereas $\mathrm{H}_{2}$ has an inhibiting effect.

Distribution of tar composition is plotted in Figure 3. It is firstly worth observing that the main contribution to total tar production comes from class 4 tars (i.e. light aromatic hydrocarbons [8][11]). As can be seen, not only is total tar concentration reduced right from the beginning of the devolatilization stage, but also the mechanism of tar destruction seems to be modified, thus indicating the addition of the oxygen transport phenomenon into the process. With non-pre-oxidized bed material, class 3, 4 and 5 tars are reduced in time but class 2 tars (i.e. heterocyclic components) start to increase after 2 hours operation. On the contrary, when pre-oxidized olivine is used, not only is production of class 3,4 and 5 reduced due to additional oxidation of tars in reduction reactions of iron oxides, but also class 2 tars start to be produced right from the beginning, thus possibly indicating that tar cracking is also improved by the increased oxygen transport. In addition, it is interesting to observe that previous oxidation of olivine including char combustion (i.e. cycle 2, test 2) makes olivine more active towards 
destruction of class 4 and 5 tars. Lastly, it should be taken into account the likely effect of char build-up on the overall tar reduction, especially at very long operating times. Assessment of this effect by comparing tar trends using inert bed material (e.g. sand) should be performed in future tests.
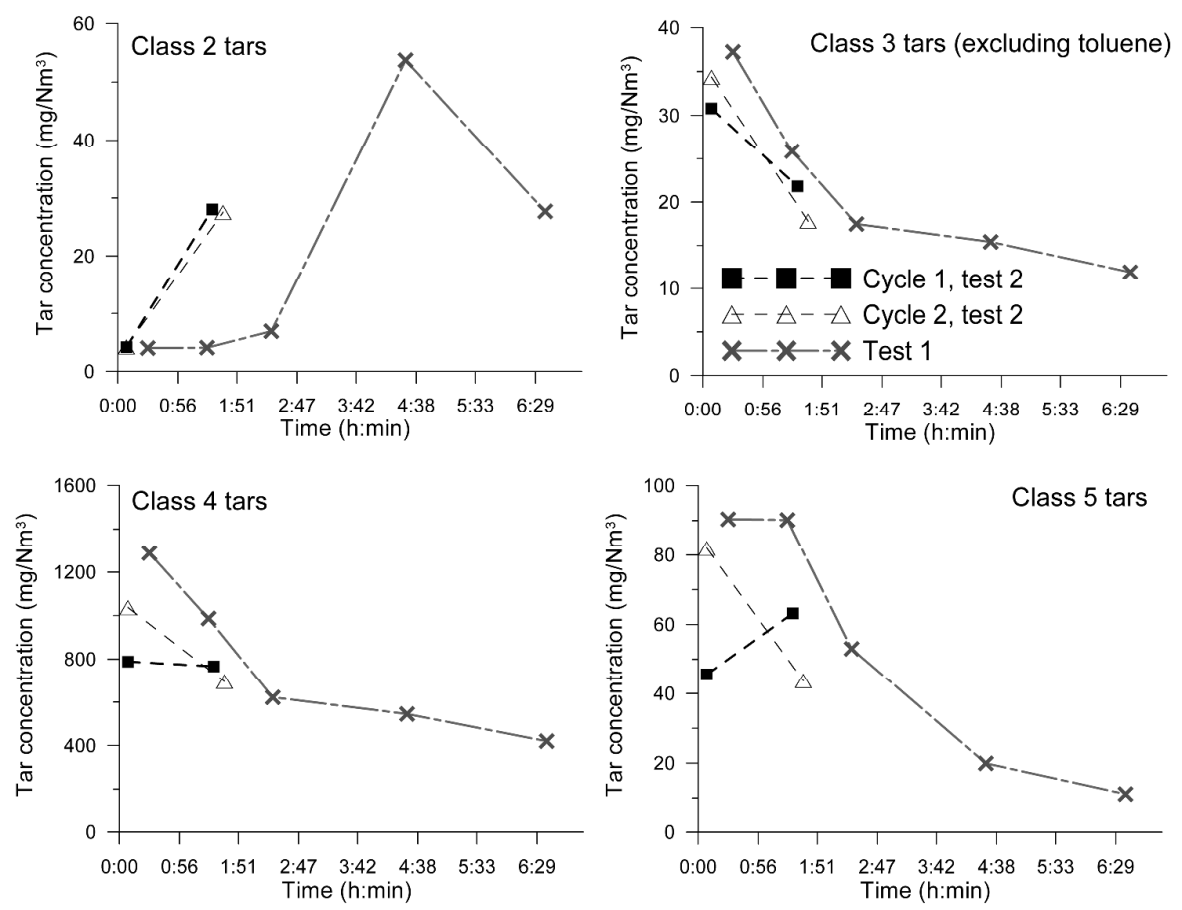

Figure 3 Effect of olivine pre-oxidation on distribution of tar composition.

Therefore, even though there is a progressive decrease in time of tar production regardless of the pretreatment conditions of the bed material, pre-oxidation of olivine leads to a very fast initial reduction of olivine when switching to gasification atmosphere, which enhances tar decomposition, particularly tar cracking of heavy tars into lighter compounds and partial oxidation of heavy tars. Results obtained are consistent with literature. The nature of the initial thermal treatment (oxidation/reduction) has been found to have a crucial influence over the behavior and catalytic properties of olivine, since it affects both the Fe content and the Fe-phase at the particle surface [4][8][9]. Pre-treatment of olivine leads to surface enrichment or depletion of Fe, as well as a change of oxidation state of the Fe species at the surface (from fully oxidized $\mathrm{Fe}^{3+}$ to largely reduced $\mathrm{Fe}^{2+} / \mathrm{Fe}^{0}$ ) [5], and the catalytic activity of olivine towards degradation of organic compounds was found to be significantly promoted by redox-type pretreatment [6][7][8][12].

Therefore, results of tar production point out the role of oxygen transport on tar destruction, thus improving the catalytic effect of olivine itself. Oxygen transport capability of olivine has been quantified by the Equivalence Ratio, $E R$. This parameter is defined as the equivalent oxygen mass added to the system by oxygen transport, $\dot{m}_{O}$ 
with respect to the stoichiometric mass amount of oxygen required to oxidize the fuel added in the same time period, $\left.\dot{m}_{O}\right|_{\text {stoic }}$, as shown in (Eq. 1):

$$
E R=\frac{\dot{m}_{O}}{\left.\dot{m}_{O}\right|_{\text {stoic }}}
$$

For the calculation of $\left.\dot{m}_{O}\right|_{\text {stoic }}$, the stoichiometric oxidation reaction of dry, composition of ash-free beech wood was used. On the other hand, $\dot{m}_{O}$ was obtained from mass balances performed to both devolatilization stages of test 2 over time intervals of 1 minute.

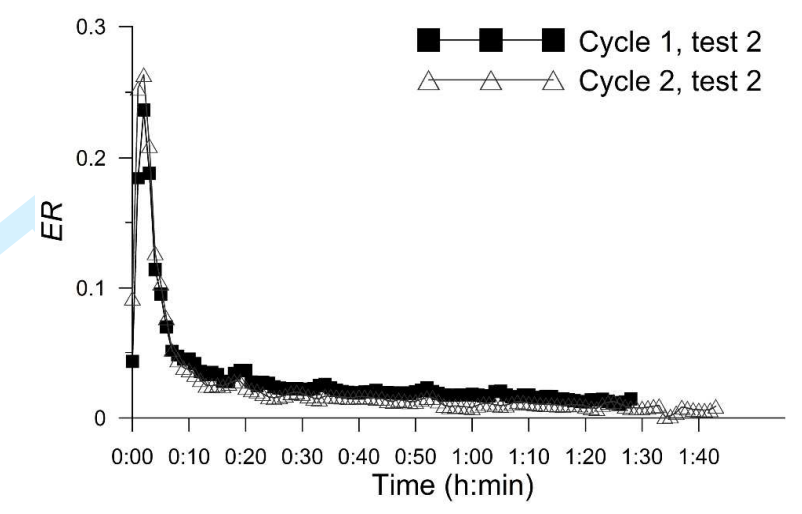

Figure 4 Equivalence ratio associated to oxygen transport by olivine.

As can be seen in Figure 4, and in consistency with previous results, ER shows a similar trend for both redox cycles applied in test 2, i.e. a sharp peak during the first minutes of operation. It is worth observing that at the maximum point, the iron oxides in olivine are able to transport an oxygen amount equivalent to $E R=0.25$. As a reference, values of $E R \sim 0.1$ were found in previous MILENA tests using the same bed material. However, it is important to remark that the assessment of oxygen transport in real indirect gasifiers by the equivalence ratio $E R$ must be linked to the circulation rate of bed material (which cannot be simulated in these tests). By integrating the mass of oxygen transport over time (considering the first ten minutes operation corresponding to the initial $\mathrm{CO}_{2}$ peak as the most representative of oxygen transport in the whole devolatilization stage), taking into account that the iron content in the olivine used in the tests is $6.3 \%$ wt., and assuming that $51 \%$ of iron in oxidized olivine is in form of free iron oxides [5], it has been estimated that 20-25\% wt. of iron in olivine is available for redox reactions during the initial sharp peak of oxygen transport. As a comparison, Lancee et al. found in TGA tests simulating redox cycles that $18 \%$ of iron in olivine is capable of transferring oxygen on time scales of one to several minutes [5].

Therefore, there are three different effects taking place during oxidation/reduction cycles of olivine in indirect gasification: 
1. Oxygen transport by olivine which leads to the release of $\mathrm{H}_{2} \mathrm{O}$ and $\mathrm{CO}_{2}$ under reducing conditions according to the diagram shown in Figure 5. On the one hand, a fraction of $\mathrm{CO}, \mathrm{H}_{2}$ and hydrocarbons ( $\mathrm{HC}$, including tars) is oxidized during the reactions of iron oxides reduction, thus contributing to the overall decrease in tar production and also releasing heat into the process. On the other hand, produced $\mathrm{H}_{2} \mathrm{O}$ and $\mathrm{CO}_{2}$ provide a significant source of additional gasifying agent available to react with char and tars via reforming reactions, which enhances the catalytic activity of the reduced olivine itself, thus contributing to an increase in the overall conversion of the process.

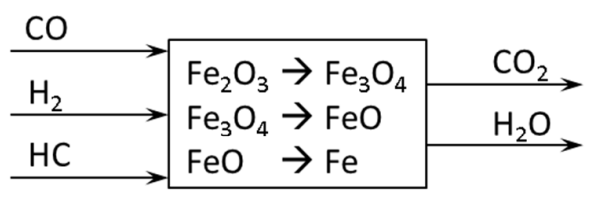

$$
\mathrm{HC}=\text { Hydrocarbons }
$$

Figure 5 Schematic diagram of oxygen transport process by iron oxides contained in olivine.

2. Iron oxides in olivine, previously segregated from the olivine matrix into the surface of the bed material during oxidation [5], are quickly reduced. The presence of metallic iron $\left(\mathrm{Fe}^{0}\right)$ is considered as an active state for tar cracking [5][9]. Virginie et al. suggest that even though tar reduction can occur without $\mathrm{Fe}^{0}$, the reaction is improved if it is present [2]. Therefore, fast reduction of iron to its metallic state is beneficial for the removal of tars from the producer gas [5]. However, whereas some authors experimentally found the presence of metallic iron during reduction of olivine under $\mathrm{H}_{2} / \mathrm{N}_{2}$ atmospheres [5], other authors state that gasification atmosphere is not reductive enough to allow iron reduction until the metallic oxidation state [2]. Further analyses to bed material samples from tests carried out in this work would be necessary to assess the phases of iron in the bed material.

3. Migration of iron back to the bulk of the olivine particle during reduction stage and into the particle surface during oxidation stage, as found by other authors [5][6].

According to the results obtained in this work in terms of producer gas composition and tar production, it seems that olivine pre-oxidation mainly influences effect 1 , that is, enhanced oxygen transport that further improves the catalytic effect of iron in olivine.

\subsection{Comparison of indirect and direct gasification}

With the aim of getting a deeper understanding on the processes taking place during indirect gasification, results from direct gasification simulating redox cycles (test 2 of this work) have been compared with those obtained in a previous gasification test performed in the $25 \mathrm{~kW}_{\text {th }}$ indirect MILENA gasifier (experimental facility described elsewhere [1][13]), using the same biomass and bed material. Comparison was performed for two operating 
points of test 2 already described in previous sections: initial maximum $\mathrm{CO}_{2}$ peak, and final stable conditions. Due to the fact that MILENA producer gas is almost $\mathrm{N}_{2}$-free $\left(1.7 \%\right.$ vol. $\left.\mathrm{N}_{2}\right)$, whereas producer gas from direct gasification test is greatly diluted in fluidizing nitrogen $\left(\sim 76-82 \%\right.$ vol. $\left.\mathrm{N}_{2}\right)$, producer gas composition has been expressed in $\mathrm{N}_{2}$-free basis for the sake of comparison. Results are depicted in Figure 6.

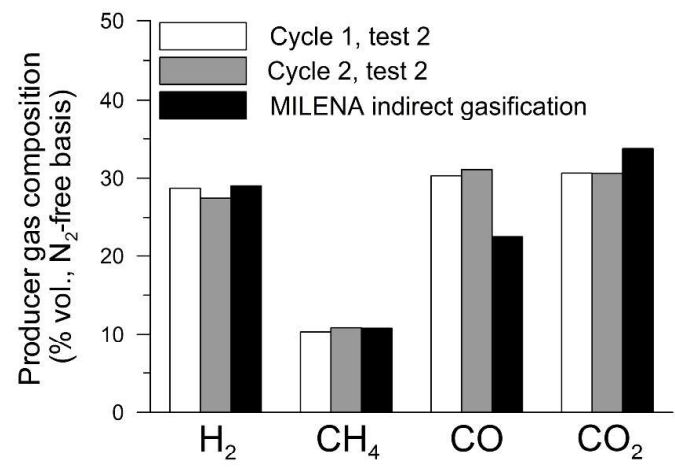

(a)

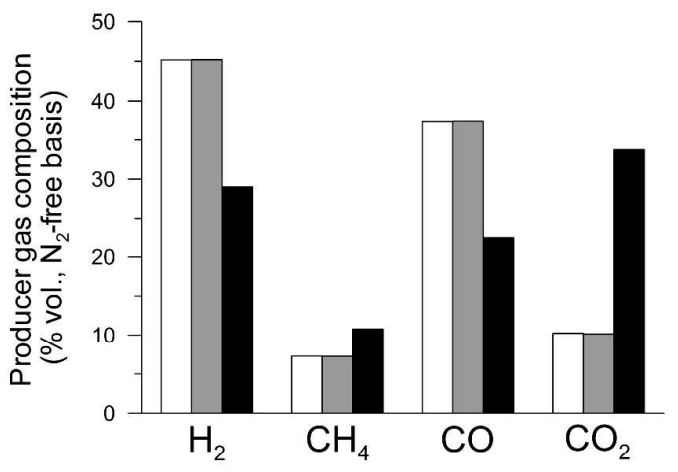

(b)

Figure 6 Comparison of $\mathrm{N}_{2}$-free producer gas composition from direct and direct gasification. Initial $\mathrm{CO}_{2}$ peak (a), final stable composition (b).

In Figure 6 it can be checked that producer gas composition from indirect and direct gasifiers is dramatically different when comparing the point of stable composition for direct gasification. $\mathrm{H}_{2}, \mathrm{CO}$ and $\mathrm{CO}_{2}$ are the compounds with highest discrepancy between both gasifiers. Nevertheless, it is interesting to realize that producer gas composition is much more similar when considering the initial point of $\mathrm{CO}_{2}$ peak. These results show that MILENA riser operates at an equivalent point of initial maximum $\mathrm{CO}_{2}$ content, where it was already found that oxygen transport and reduction of olivine are at their maximum. This implies that, even though tar destruction is greatly enhanced in this point, producer gas also contains a lot of $\mathrm{CO}_{2}$ (and $\mathrm{H}_{2} \mathrm{O}$ ) from the reactions of iron oxide reduction (see Figure 6 right).

In addition, redox combustion/gasification cycles taking place during MILENA operation allow a continuous regeneration of the olivine by ensuring that active iron is periodically available at the surface of the olivine, therefore preventing the olivine from deactivation by loss of iron dispersion, as pointed by other authors [9]. On the other hand, even though olivine is not a porous material and therefore is not likely to be significantly affected by deactivation due to carbon deposition, cyclic combustion/gasification stages might help prevent this mechanism of deactivation observed in other catalytic bed materials (e.g. nickel-based).

However, there are still some discrepancies between producer gas compositions even at the initial devolatilization point, particularly in the $\mathrm{CO}$ content. This might be attributed to differences in terms of residence time and mixing of solids. MILENA riser, equivalent to a spouted bed reactor, has residence times of 
the order of seconds and not very intense contact between olivine and biomass particles. On the contrary, although operating conditions were selected to be as similar as possible to those of MILENA riser, test 2 in this work was performed under fluidized bed conditions, i.e. gas residence times approximately below 1 minute, and improved contact between particles of olivine and biomass.

\section{CONCLUSIONS}

Gasification tests in a direct fluidized bed gasifier using activated olivine as bed material and simulating oxidation/reduction cycles have been carried out in order to study the effect of oxygen transport on the performance of olivine. Tests have also allowed comparison of the concepts of direct and indirect gasification. Results obtained have shown that:

- There is an increase in $\mathrm{H}_{2}$ and $\mathrm{CO}$ concentrations and a decrease of tar production along time regardless of the pretreatment conditions of the bed material due to the progressive reduction of iron contained in olivine, which increases its catalytic activity towards tar destruction.

- When simulating redox cycles as in MILENA indirect gasifier, fast reduction of olivine (as observed by an initial $\mathrm{CO}_{2}$ peak) takes place within the first minutes after switching from combustion to devolatilization conditions.

- Olivine pre-oxidation mainly enhances the capacity of oxygen transport of the bed material, which further improves the catalytic effect of iron in olivine towards tar destruction by oxidation and cracking of a fraction of the tars produced. Tar destruction mechanisms are also modified by olivine pre-oxidation, being class 2 tars formed while classes 4 and 5 are destroyed. Oxygen transport capacity of olivine has been quantified as $E R=0.25$ at the maximum initial $\mathrm{CO}_{2}$ peak. It has been estimated that $20-25 \%$ wt. of iron in olivine is able to transfer oxygen.

- MILENA operating conditions have been found to be equivalent to the initial maximum peak of $\mathrm{CO}_{2}$ observed in devolatilization stages of redox cycles. This means that under MILENA operating conditions, oxygen transport capacity of olivine is kept at its maximum due to the continuous combustion/gasification cycles, thus contributing to enhanced tar destruction, keeping at the same time olivine activated by cyclical migration of iron into the surface during oxidation, and subsequent fast reduction of iron oxides with additional release of $\mathrm{CO}_{2}$ and $\mathrm{H}_{2} \mathrm{O}$ by oxygen transport. Therefore, MILENA appears as a feasible technology for the use of chemical looping beyond gasification applications.

\section{Acknowledgments}

Authors are grateful to P.A. Verbraeken, M. Geusebroek and A.A. Toonen for their kind assistance in gasification tests and tar analyses. 
REFERENCES (last access to web pages: August 2013)

[1] Grootjes, A.J., van der Meijden, C.M., Visser, H.J.M., van der Drift, A. (2013). Improved gasifier availability with bed material and additives. Proceedings of the 21st European Biomass Conference and Exhibition. Copenhagen (Denmark).

[2] Virginie, M., Adánez, J., Courson, C., de Diego, L.F. (2012). Effect of Fe-olivine on the tar content during biomass gasification in a dual fluidized bed. Appl. Catal. B: Environ., 121-122, 214-222.

[3] García-Labiano, F., Adánez, J., de Diego, L.F., Gayán, P., Abad, A. Tests of efficiency of Fe/olivine and sorbents for tar reduction and trace element removal. Unique Project, deliverable 2.1. http://www.uniqueproject.eu/public/deliverables/D2.1.pdf

[4] Koppatz, S., Pfeifer, C., Hofbauer, H. (2011). Comparison of the performance behaviour of silica sand and olivine in a dual fluidised bed reactor system for steam gasification of biomass at pilot plant scale. Chem. Eng. J., 175, 468-483.

[5] Lancee, R.J., Dugulan, A.I., Thune, P.C., Veringa, H.J., Niemantsverdriet, J.W., Fredriksson, H.O.A. (2013). Chemical looping capabilities of olivine, used as a catalyst in indirect biomass gasification. App. Catal., B: Environ., doi:10.1016/j.apcatb.2013.01.041.

[6] Pecho, J., Schildhauer, T.J., Sturzenegger, M., Biollaz, S., Wokaun, A. (2008). Reactive bed materials for improved biomass gasification in a circulating fluidised bed reactor. Chem. Eng. Sci., 63 (9), 2465-2476.

[7] Pecho, J., Sturzenegger, M. (2004). Elucidation of the function of olivine in biomass gasification. PSI Scientific Report, Annex V. http://solar.web.psi.ch/data/publications/pdf2/Pecho\%202004.pdf

[8] Devi, L. (2005). Catalytic removal of biomass tars; Olivine as prospective in-bed catalyst for fluidized-bed biomass gasifiers. Doctoral Thesis, Eindhoven University of Technology. ISBN: 90-386-2906-0.

[9] Kuhn, J.N., Zhao, Z., Felix, L.G., Slimane, R.B., Choi, G.N., Ozkan, U.S. (2008). Olivine catalysts for methane- and tar-steam reforming. Appl. Catal. B: Environ., 81, 14-26.

[10] Energy research Centre of the Netherlands, Phyllis2, database for biomass and waste, http://www.ecn.n1/phyllis2

[11] Energy research Centre of the Netherlands. Thersites, the ECN tar dew point site. www.thersites.nl

[12] Vilela, C. (2012). Primary methods in biomass gasification for gas conditioning and cleaning. Doctoral Thesis, Eindhoven University of Technology. ISBN: 978-90-386-3247-6.

[13] van der Meijden, C.M. (2010). Development of the MILENA gasification technology for the production of Bio-SNG. Doctoral Thesis, Eindhoven University of Technology. ISBN: 978-90-386-2363-4. 
